\title{
Outcomes from hospitalised acute exacerbations of COPD: a bundle of optimism?
}

\author{
William D-C Man, ${ }^{1,2}$ Ruth Barker, ${ }^{1}$ Matthew Maddocks, ${ }^{3}$ \\ Samantha S C Kon ${ }^{1,2,4}$
}

Exacerbations of COPD place enormous stress on acute healthcare systems-they are one of the most common causes of emergency hospital admission and frequently result in readmission. Acute healthcare provision in England and Wales has adapted to deliver 'front-door' efficiency, with the rise of acute physicians and an emphasis on seeing hospitalised patients quickly to improve safety and facilitate early discharge-an example of the popular healthcare improvement mantra that 'every system is perfectly designed to get the results it gets'. From this perspective, the results of the most recent national secondary care COPD audit are highly satisfying, demonstrating reduced inpatient mortality and length of stay. ${ }^{1}$ However, there is substantial national variation in acute care ${ }^{1}$ and readmission rates remain worryingly high, with more than $60 \%$ of patients readmitted to hospital at least once in the year following discharge. ${ }^{2}$

Outcomes from acute exacerbations of COPD are dependent on several factors beyond quality of care. These include the severity of the acute event, whether physiological derangements respond and improve to treatment during the admission, ${ }^{3}$ the baseline severity of respiratory disease in the individual, the influence of comorbidities and extra-pulmonary manifestations such as sarcopenia and frailty, ${ }^{4-7}$ and the individual's self-management skills and resilience. ${ }^{8}$

This is illustrated in the work of Hodgson et $a l^{9}$ which demonstrates that the National Early Warning Score (and supposed respiratory patient-specific varia-

\footnotetext{
${ }^{1}$ NIHR Respiratory Biomedical Research Unit, Royal Brompton and Harefield NHS Foundation Trust and Imperial College, London, UK; ${ }^{2}$ Hillingdon Integrated Respiratory Service (HIRS), London, UK; ${ }^{3}$ King's College London, Cicely Saunders Institute, London, UK; ${ }^{4}$ The Hillingdon Hospitals NHS Foundation Trust, London, UK

Correspondence to Dr William Man, Department of Respiratory Medicine, Harefield Hospital, Hill End Road, Harefield UB9 6JH, UK; w.man@rbht.nhs.uk
}

tions), which identifies acute physiological derangements, has only modest discrimination in predicting inpatient mortality in COPD. Measuring change in physiological derangements during an admission gives added information, ${ }^{3}$ while the composite DECAF (Dyspnoea Score, Eosinopenia, Consolidation, Acidaemia, atrial Fibrillation) score, which includes a baseline measure of respiratory disability, and clinical indicators of the admission severity show much better discrimination for in-hospital mortality. ${ }^{10}$

It is difficult to entirely divorce what occurs during the acute inpatient stay with what occurs in the post-discharge period and beyond, and it is important to remember that even for a 'revolving door' patient, much greater time is spent outside than inside the acute hospital setting. Furthermore, from the patient perspective, a hospitalisation is a devastating life-event with significant physical and psychosocial ramifications $^{11}$ that persist beyond the typical hospital stay following an acute exacerbation of COPD. To standardise and potentially improve the delivery of post-discharge care in COPD, there is growing enthusiasm for the role of discharge bundles to provide a structured aide memoire of evidence-based practices $^{12} 13$ that can be delivered for all patients with a condition, irrespective of ward, specialty or profession delivering care. Typically, a bundle should contain three to five practices that, when performed collectively and reliably, improve patient outcomes. However, as is often the case with interventions developed from quality improvement initiatives, the accompanying evidence has largely arisen from uncontrolled before study and after study designs with an inherent high risk of bias.

The systematic review of Ospina et $a l^{14}$ in this issue of Thorax is therefore welcome in collating current available evidence for discharge bundles in COPD. The authors were able to perform meta-analyses using data from randomised controlled trials, which demonstrated that discharge bundles were associated with fewer readmissions, but with no impact on health-related quality of life or mortality. These findings are perhaps not as optimistic as some would hope for and certainly not as impressive as findings from trials and systematic reviews of post-hospitalisation pulmonary rehabilitation. ${ }^{15-18}$

Ospina et al highlight several practical issues surrounding discharge bundles. Consensus is lacking as to the optimal number of components in a bundle or which components are considered core and optional. There was significant heterogeneity in both the number and type of components, ranging from 2 to 12 components of 26 distinct interventions that were included within discharge bundles. Included studies often did not provide information on how the components of the bundle were generated or chosen. Some components would be considered good practice and common sense, for example, assessing use of medications, but have not been rigorously tested in the post-discharge period. Remarkably, there was not a single common intervention across the discharge bundles described in the four randomised controlled trials included for meta-analysis for readmissions. This raises the issue of whether a 'one size fits all' discharge bundle, appropriate for all patients and localities, can or even should be realised. A recent study in Thorax has shown that gait speed, a simple surrogate marker of frailty, measured on the day of hospital discharge showed excellent discrimination in predicting readmission in older patients with COPD. ${ }^{4}$ This demonstrates the large heterogeneity in readmission risk between individuals $^{3} \quad 4$ and distinct cohorts of patients with complex needs that might require increased and more individualised input than can be offered through a discharge bundle.

The implementation of discharge bundles can also be challenging. A recent retrospective study identified 28 different barriers, many of which related to staff resources and engagement. ${ }^{19}$ Patient-related factors, such as cognitive impairment or psychological distress, can also have a significant impact on implementation. ${ }^{11}$ Even with broad staff and patient acceptance of a discharge bundle, there is little guarantee that the individual components can be actioned. For example, the recent snapshot audit of pulmonary rehabilitation services in England and Wales revealed very patchy provision of post-hospitalisation pulmonary 
rehabilitation. Even in local healthcare systems where a discharge bundle is in use and where there are adequate pulmonary rehabilitation services, referral to and completion of post-hospitalisation pulmonary rehabilitation is disappointing. ${ }^{20}$

Although the systematic review from Ospina et al demonstrates the potential value of discharge bundles, larger trials of higher methodological quality are required to strengthen the evidence base around their effectiveness. Discharge bundles are conceptually simple and attractive but are unlikely to achieve their desired effects or full potential without greater consideration of the challenges associated with implementation. Dr W Edwards Deming, the American statistician and management consultant who was credited as the inspiration for the post-war Japanese economic recovery, believed that quality could be improved with costs reduced simultaneously by practising continual improvement and thinking of productivity as a system and not as individual components. Discharge bundles are only one component of a wider integrated system of care for COPD and their true value perhaps lies in facilitating better integration between acute and chronic care for this patient population.

Competing interests None declared.

Provenance and peer review Commissioned; externally peer reviewed.

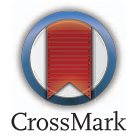

To cite Man WD-C, Barker R, Maddocks $M$, et al. Thorax 2017;72:8-9.

Published Online First 18 October 2016

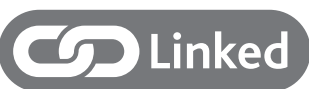

- http://dx.doi.org/10.1136/thoraxjnl-2016-208820

http://dx.doi.org/10.1136/thoraxjnl-2016-208436

Thorax 2017;72:8-9

doi:10.1136/thoraxjnl-2016-209212

\section{REFERENCES}

1 Stone RA, Holzhauer-Barrie J, Lowe D, et al. COPD: Who cares matters. National Chronic Obstructive Pulmonary Disease (COPD) Audit Programme: Clinical audit of COPD exacerbations admitted to acute units in England and Wales 2014. National Clinical Audit Report. London: RCP, 2015.

2 Greening NJ, Williams JE, Hussain SF, et al. An early rehabilitation intervention to enhance recovery during hospital admission for an exacerbation of chronic respiratory disease: randomised controlled trial. BMJ 2014;349:g4315

3 Suh ES, Mandal S, Harding R, et al. Neural respiratory drive predicts clinical deterioration and safe discharge in exacerbations of COPD. Thorax 2015;70:1123-30.

4 Kon SS, Jones SE, Schofield SJ, et al. Gait speed and readmission following hospitalisation for acute exacerbations of COPD: a prospective study. Thorax 2015;70:1131-7.

5 Jones SE, Maddocks M, Kon SS, et al. Sarcopenia in COPD: prevalence, clinical correlates and response to pulmonary rehabilitation. Thorax 2015;70:213-18.

6 Maddocks M, Kon SS, Canavan JL, et al. Physical frailty and pulmonary rehabilitation in COPD: a prospective cohort study. Thorax2016;71:988-95.

7 Greening NJ, Harvey-Dunstan TC, Chaplin EJ, et al. Bedside assessment of quadriceps muscle by ultrasound after admission for acute exacerbations of chronic respiratory disease. Am J Respir Crit Care Med 2015;192:810-16.

8 Bucknall CE, Miller G, Lloyd SM, et al. Glasgow supported self-management trial (GSUST) for patients with moderate to severe COPD: randomised controlled trial. BMJ 2012;344:e1060.

9 Hodgson LE, Dimitrov BD, Congleton J, et al. A validation of The National Early Warning Score to predict outcome in patients with COPD exacerbation. Thorax 2017;72:23-30.

10 Steer J, Gibson J, Bourke SC. The DECAF Score: predicting hospital mortality in exacerbations of chronic obstructive pulmonary disease. Thorax 2012;67:970-6.

11 Man WDC, Puhan MA, Harrison SL, et al. Pulmonary rehabilitation and severe exacerbations of COPD: solution or White elephant? ERJ Open Res 2015;1:00050-2015.

12 Hopkinson NS, Englebretsen C, Cooley N, et al. Designing and implementing a COPD discharge care bundle. Thorax 2012;67:90-2.

13 Turner AM, Lim WS, Rodrigo C, et al. A care-bundles approach to improving standard of care in AECOPD admissions: results of a national project. Thorax 2015:70:992-4.

14 Ospina MB, Mrklas K, Deuchar L, et al. A systematic review of the effectiveness of discharge care bundles for patients with chronic obstructive pulmonary disease. Thorax 2017;72:31-9.

15 Man WD, Polkey MI, Donaldson N, et al. Community pulmonary rehabilitation after hospitalisation for acute exacerbations of chronic obstructive pulmonary disease: randomised controlled study. BMJ 2004;329:1209.

16 Puhan MA, Gimeno-Santos E, Scharplatz M, et al. Pulmonary rehabilitation following exacerbations of chronic obstructive pulmonary disease. Cochrane Database Syst Rev 2011;(10):CD005305.

17 Seymour JM, Moore L, Jolley CJ, et al. Outpatient pulmonary rehabilitation following acute exacerbations of COPD. Thorax 2010;65:423-8.

18 Maddocks M, Kon SS, Singh SJ, et al. Rehabilitation following hospitalization in patients with COPD: can it reduce readmissions? Respirology 2015;20: 395-404.

19 Lennox L, Green S, Howe C, et al. Identifying the challenges and facilitators of implementing a COPD care bundle. BMJ Open Respir Res 2014; 1:e000035.

20 Jones SE, Green SA, Clark AL, et al. Pulmonary rehabilitation following hospitalisation for acute exacerbation of COPD: referrals, uptake and adherence. Thorax 2014;69:181-2. 